\title{
Complications of sclerotherapy
}

\author{
Malay Patel (D, Roy Varghese (D, Manjusha Rajarshi (D) \\ First Choice Vascular, Vascular-Endovascular-Phlebology, Ahmedabad, India
}

\begin{abstract}
Sclerotherapy is a popular, simple, safe, and effective alternative to ablation of refluxing veins in patients with chronic venous insufficiency due to chronic venous disease. Over the last two decades, we have used this method and its safer variant of ultrasound-guided foam sclerotherapy, solely or adjunctly, to ablate all types of superficial refluxing veins. In the course of therapy, we observed some complications, managed them, and discuss them in this review, along with some which have been reported in the literature. Our effort is to increase the use of this safe and straightforward method to ablate superficial refluxing.
\end{abstract}

Keywords: Allergic reactions, complications, sclerosants, ultrasound-guided foam sclerotherapy.

Chronic venous insufficiency (CVI) is a condition that affects almost a third to half of the general population and, in the vast majority, it is due to reflux in the superficial venous system of the lower extremities. Varicose veins ( $\mathrm{VVs}$ ) are the dilated and tortuous superficial veins and are part of chronic venous disease (CVD) with a high healthcare burden. ${ }^{[1,2]}$ The VVs are caused due to incompetent valves, structural changes in vein walls, inflammation, alteration in shear stress, decreased elasticity causing reflux, and blood pooling in superficial veins leading to venous hypertension. The condition can lead to skin changes, ulceration in the lower legs, and phleboarthrosis of the knee and foot joints, if not intervened timely. The effects of the disease are controllable by intervention: the sooner, the better. One of the most uniform prevalence estimations for the overall prevalence of venous ulcers shows that around $1 \%$ of the adult population has a history of healed or open venous ulcers in the legs. ${ }^{[3,4]}$

Lower extremity VVs are relatively common with a reported prevalence ranging between 10 and 30\% worldwide. The etiology of VVs has not been fully elucidated yet; however, several contributing factors have been identified including increasing age, female sex, family history of venous diseases, pregnancy, smoking, and higher baseline body mass index (BMI). Prolonged working in a standing position is considered an essential contributory occupational risk factor in susceptible individuals. ${ }^{[5]}$

Varicose veins are characterized by pain, itchiness, heavy sensation, pigmentation and, when left untreated, lead to leg ulcerations. There are various modalities of treatment of VVs. The modalities range from conservative to invasive and include compression stockings, injection sclerotherapy, open surgeries, and minimally invasive interventions. ${ }^{[6,7]}$

As a treatment for VVs, foam sclerotherapy (FS) has a historical reportage that dates back to 1939 when injections of sodium morrhuate were administered into the spider veins. ${ }^{[8]}$ Foote $^{[9]}$ and Sigg ${ }^{[10]}$ introduced FS injections around 1949, and Orbach ${ }^{[11]}$ experimented with the efficacy of sodium tetradecyl sulfate (STS) foam. Its use in patients was reported between 1953 and 1956 by the Norwegian, Arve Ree Fluckiger. ${ }^{[12]}$

Received: February 21, 2021 Accepted: February 28, 2021 Published online: April 16, 2021

Correspondence: Malay Patel, MD. First Choice Vascular, Vascular-Endovascular-Phlebology, 380009 Ahmedabad, India. e-mail: info@drmalaypatel.com 
These early concepts are now widely used and practiced under the ultrasound guidance. ${ }^{[13]}$

Over the last two decades, ultrasound-guided foam sclerotherapy (UGFS) has become a popular method for eliminating superficial venous reflux (SVR) by endoablation and used increasingly more widely not only to supplement truncal ablation, but also as a standalone therapy to treat refluxing trunks and tributaries with endoablation gels with the idea of making procedures as minimally invasive as possible. Current techniques of endoablation provide satisfactory clinical outcomes. However, some complications can be encountered. In this review, possible complications with sclerotherapy are summarized and some preventive measures and guideline recommendations are discussed. ${ }^{[14]}$

Better understanding of the physicochemical properties of sclerosants as well as their delivery mechanisms have resulted in overall infrequent complications. Foaming of the sclerosant increases its effectiveness to disrupt cell membranes, particularly the cell membranes of the endothelium of the refluxing veins, to induce a thrombotic/sclerosing reaction leading to closure of the vein. The closure takes away the reflux and effectively reduces the back-pressure effects of the venous blood. This closure is the basis for the effectiveness of endoablation.

\section{Endoablation}

\section{Principles and techniques in the management of CVI}

The typical way of treating CVI is eliminating the reflux in a superficial vein by surgical extirpation or endoablation. Over the last two decades, endoablation has emerged as the dominant method of treating SVR. Within the domain of endoablation, two subdomains have emerged: tumescent and non-tumescent.

Tumescence is most commonly used, when endoablation is done by applying heat to induce thermal damage to the endothelium, and is known as thermal endoablation. Non-tumescent endoablation primarily utilizes a chemical introduced intra-luminally into the trunk or tributary of the superficial vein under ultrasound guidance-the chemical allows to exerts its effect to obliterate the vein and is known as chemical endoablation. The move toward using non-tumescent endoablation is guided by making procedures simpler.

Tumescent endoablation, as the name implies, is usually done after a biocompatible solution is injected around the target vein to produce tumescence. The tumescence producing solution is typically a combination of saline, lidocaine and a buffer, injected around the trunk of the great saphenous vein in the thigh and upper leg under ultrasound guidance and forms a heat-sink to minimize thermal damage to tissues surrounding the target vein. Tumescence also produces external compression of the vein and reduces its diameter.

Chemical endoablation with FS has been used for the last several decades; however, it gained its popularity particularly within the last two decades, especially UGFS, despite competition from rival methods. As it has been increasingly used, it brings some concerns regarding the safety of the sclerosants used. To date, serious complications have been very rarely noted; however, some common complications have been described. For starters, this appeared to be a reason for caution; nevertheless, time has shown that UGFS is extremely safe and well-tolerated if a particular attention to avoid complications is paid.

\section{Complications of UGFS are local and systemic}

\section{Local complications}

Categorized chronologically

1. Cutaneous necrosis and tissue loss: Development of a bleb, wheal, pallor, blanching, localized severe pain, paresthesia and even paralysis occurring while injecting or within a few min of completing the injection, despite an intravenous injection is indicative of traverse of foam retrogradely via a circuitous route into a dermal arteriole or arteriole feeding a varicose vein and/or reflex arteriolar spasm. An intra-arterial injection is likely even under ideal circumstances and, if any back-bleed is noticed that can retrogradely overcome the break loose/force of the syringe, then stop injecting. When in doubt it is best to withdraw the needle and choose another site. Inadvertent intra-arterial injection is the commonest cause for cutaneous necrosis and takes great and sustained effort to minimize the inevitable full-thickness dermal damage, as well as bringing about healing. Fortunately, it is very rare. ${ }^{[15-20]}$ Another cause of cutaneous necrosis is development of perivenulitis in a vein that lies just subdermal. The secondary inflammatory reaction can be compounded by the leaching of the sclerosant, leading to damage the full thickness of the skin. Reflex arteriospasm is also a likely cause for producing full thickness skin necrosis (Figures 1, 2). 


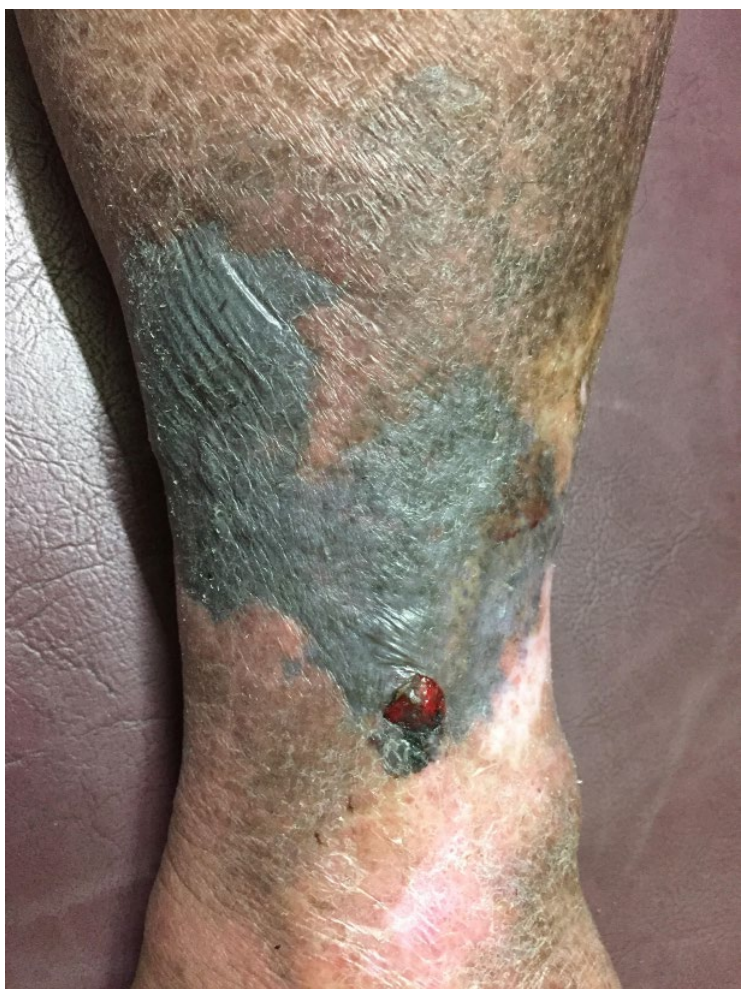

Figure 1. Cutaneous necrosis following inadvertent arterial injection.

2. Superficial thrombophlebitis: The term thrombophlebitis evokes discussion and implies an inflammatory reaction. Sclerosant solutions produce inflammation and, thus, it is correct to suggest that thrombophlebitis occurs. Thrombophlebitis is brought to the attention of both patient and doctor by an area of redness and warmth on the skin that is painful and tender. In general, it is an elevated patch that corresponds to an underlying bunch of varicosities or reticular veins or spider veins/telangiectasias or a complex containing all or some of these elements. It typically appears in less than a week and is most often seen in varicosities that are close to the skin or were bulging through the skin.

3. Superficial thrombosis: It is caused by a clot in a vein that may or may not extend. In the majority of cases, it stays limited to the vein that is treated, but in the lower leg, particularly at connections to the deep system via a perforator, it may have a propensity to extend into the deep veins. The extension is usually limited to a short segment of 3 to $4 \mathrm{~cm}$ and is an incidental observation and does not require

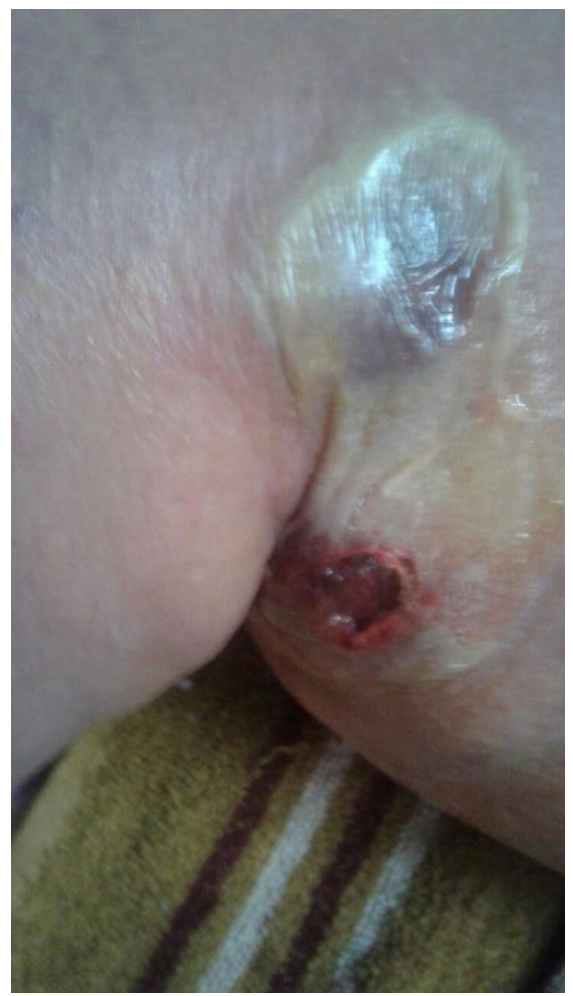

Figure 2. Cutaneous necrosis due to inflammatory reaction extending to surface of skin.

additional treatment with anticoagulation. If an ultrasound of the underlying treated superficial varicosity shows compressibility, echo-lucent areas, greyscale movement, color flashes on routine Duplex or with power Doppler, then aspirate and inject additional sclerosant. Usual measures of cold application alleviate and shorten the course of suffering (Figure 3). ${ }^{[21-23]}$

4. Pigmentation: Post-sclerotherapy pigmentation occurs in about 10 to $30 \%$ of patients and occurs as linear streaking along the course of an underlying treated vein usually between 0.1 and $5 \mathrm{~mm}$ in size and the usual mechanism is a perivenulitis ${ }^{[24]}$ due to the extrusion of red blood cells from within the vein lumen into the surrounding tissue and getting deposited as hemosiderin. The contribution of the melanocytic system is minimal. The pigmentation is more intense and persistent with concomitant use of minocycline and, if possible, avoid combining both. Although evidence to exposure to sunlight is lacking, an advice to avoid sunlight exposure is given. Dark-skinned individuals also show higher 


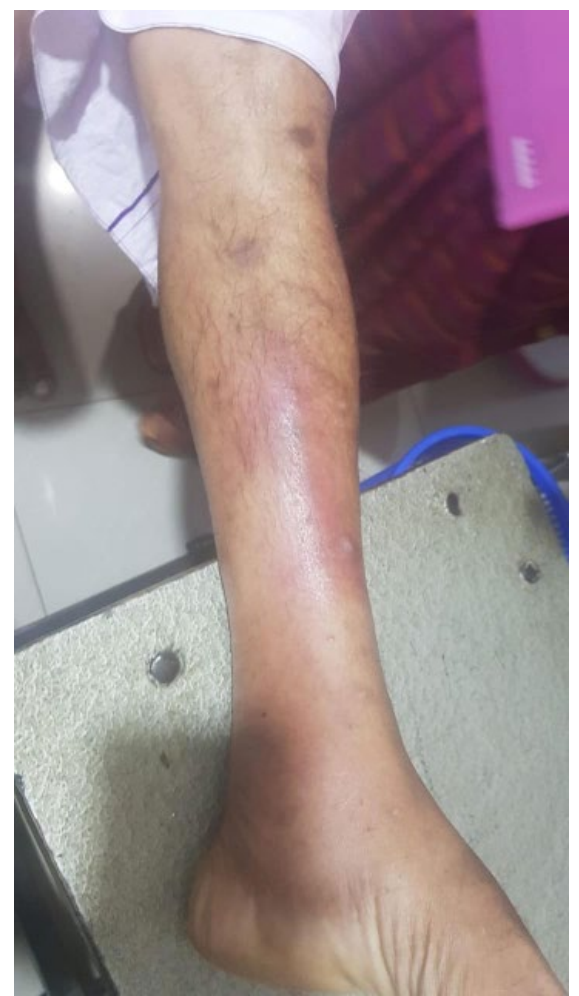

Figure 3. Superficial thrombophlebitis seen as linear red areas along the course of the treated vein.

rates of hyperpigmentation. More than $80 \%$ of pigmentation would fade over time with most disappearing by one year. Persistent pigmentation can be treated with intense pulsed light generator, equipped with radiofrequency with complete disappearance in 90\% (Figure 4).

5. Telangiectatic matting: It is a post-sclerotherapy neovascularization that develops overlying and near a treated superficial vein. It occurs in about 15 to $20 \%$ of patients about four to six weeks after treatment and resolves within three to 12 months. Neovascularization appears as a new area of telangiectasia and probably indicates unmasking of subclinical capillary veins due to dilatation or development of alternate venous drainage channels. Careful ultrasound or search by powerful transillumination under this area may reveal a reflux from a residual vein, perforator or feeding reticular vein. A probable mast cell-induced pathway and association with hypersensitivity, easy bruising and epistaxis have been described. ${ }^{[22,25-28]}$

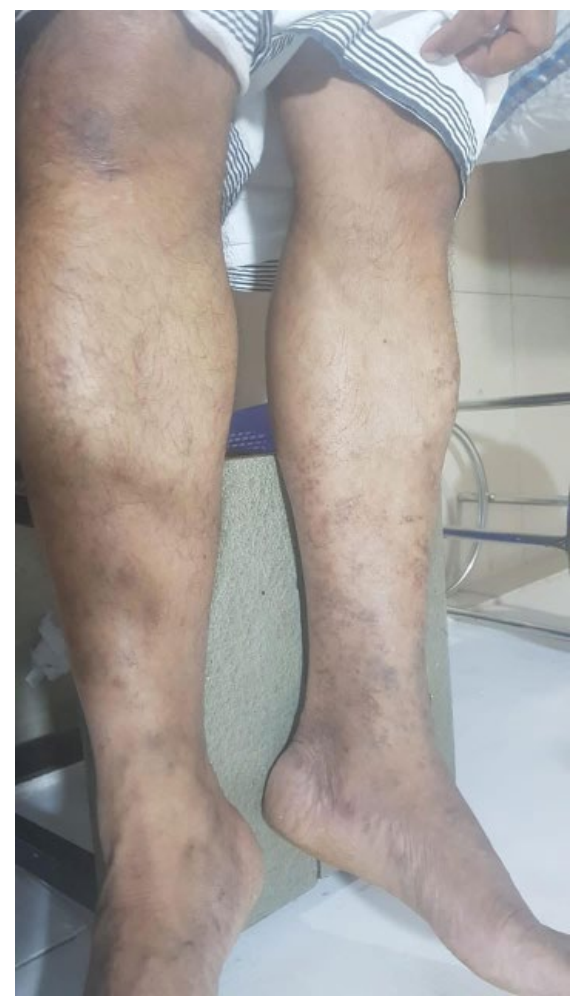

Figure 4. Hyperpigmentation occurring along the treated vein.

6. Nerve injury: Transient saphenous or sural nerve injury usually resolve within four to six months. These nerves lie in close proximity to the great or short saphenous vein in the lower leg. Current ultrasound is very efficient in visualizing nerves and their identification and visualization should be routine. Identification under ultrasound before injection minimizes these injuries. ${ }^{[29]}$

7. Bruising: Bruising can occur at an injection site and probably it is due to the back-bleed of venous blood from the needle hole as a result of retrograde venous hypertension (Figures 5 and 6).

\section{Systemic complications}

Categorized chronologically

1. Allergic reactions: Allergic reactions have been anecdotally reported ranging from development of skin rashes to fatal anaphylactic/anaphylactoid reactions. They are very rare with current commonly used pharmacological sclerosants that are manufactured in accordance with the good 


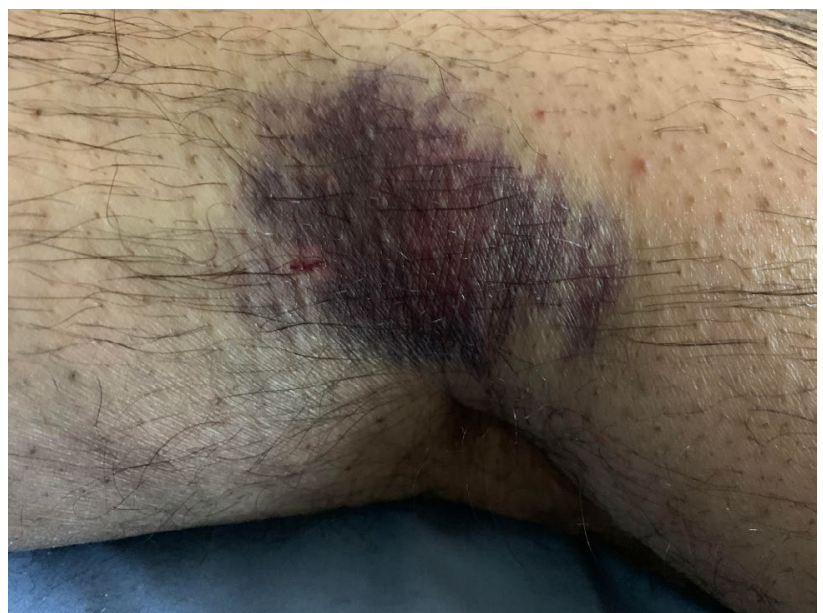

Figure 5. Bruising seen around the injection site and overlying a varicosity.

manufacturing practices. The mechanism of action appears to be mediated through the mast cell-histamine pathway. Any history of allergic reactions such as asthma or skin rashes is a relative contra-indication to sclerotherapy. Pre-medication with antihistamines can drastically reduce or prevent allergic reactions.

2. Chest heaviness: Following sclerotherapy, chest discomfort and/or heaviness accompanied by coughing that is transient have been described related to the use of air. Use of carbon dioxide or a combination of carbon dioxide and oxygen has nearly eliminated this post-procedural discomfort. The probable mechanism appears to be arteriolar occlusion due to gas bubbles.

3. Cough: It is postulated that micro-bubbles of air enter the arterioles of the alveoli and cause a spasm, resulting in coughing.

4. Cerebrovascular reactions: Serious cerebrovascular events were reported in the past; however, with refinement in technique, caution in therapy or avoiding therapy, in those with underlying systemic conditions such as right-to-left shunt, asthma, and migraine, cerebrovascular reactions are very rare. Their incidences have decreased dramatically and, currently, are well below 1\%. Transient ischemic events are very rare and are mediated by the endothelin pathway. Full recovery occurs. Prevention in susceptible individuals or those previously affected can be controlled by use of endothelin receptor blockers or endothelin antagonists. $^{[30-32]}$

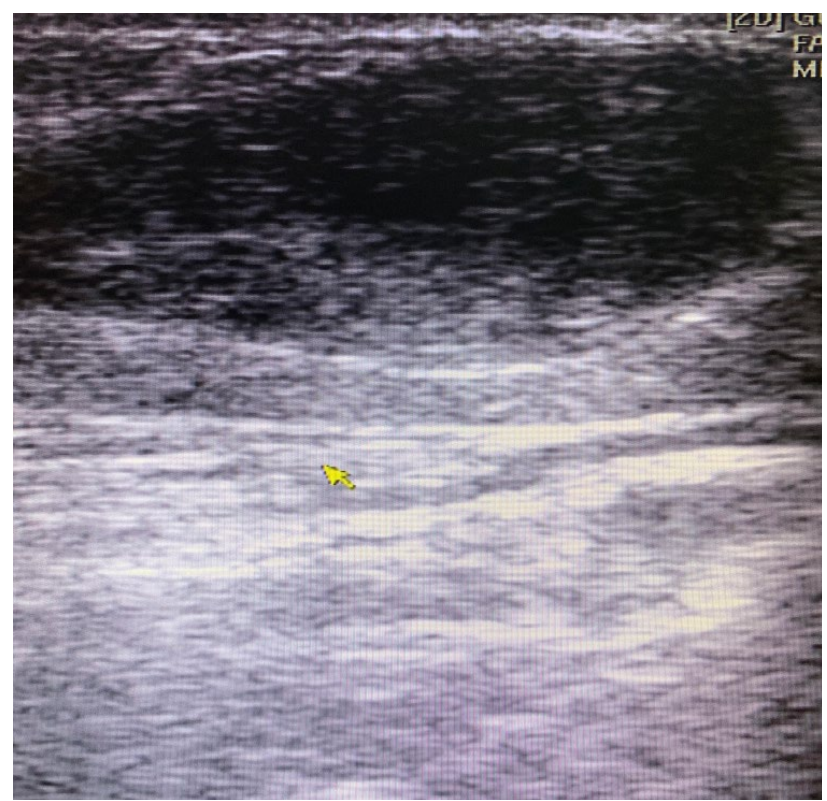

Figure 6. Treated varicosity under the same bruised skin showing adequate sclerosant action.

5. Cardiovascular reactions: Anecdotally, sclerotherapy has been associated with myocardial infarction and Takotsubo cardiomyopathy. Cardiac function in case of Takotsubo cardiomyopathy returns to normal within three days of presentation. ${ }^{[33-37]}$ Theoretically, polidocanol may have negative inotropic and chronotropic effects on the heart. In practice, this is extremely rare and may be transient. It is almost impossible for the active sclerosant to reach the heart, since the sclerosant is deactivated by every component of blood including serum proteins. ${ }^{[38]}$

6. Deep vein thrombosis and pulmonary embolism: The incidence of deep vein thrombosis is insignificant and, hence, goes unreported now. Previous studies have shown an incidence of 0 to $5.7 \%$. Anecdotal report of pulmonary embolism has been published. ${ }^{[39]}$

7. Infection: Secondary infection of the treated area is rare, but can occur leading to systemic invasion of bacteria with its sequelae. It is a localized area of pain, redness, warmth, and swelling that prompts the clinician to suspect it, and any spread of the redness and pain should alert one to a spread. Systemic enteral or parenteral antibiotics are helpful for infection control. 


\section{DISCUSSION}

Chronic venous insufficiency is characterized by cutaneous alterations caused by venous hypertension; in severe forms, it progresses to lower limb ulcers. Lower limb VVs are the main cause of CVI, and the classic treatment includes surgery and compressive therapy. The treatment for primary VVs considered for the lower extremities is usually minimally invasive, repeated when necessary, and free from significant complications, as well as should be effective in eliminating the reflux points and venous hypertension at the extremities. ${ }^{[40]}$ The UGFS is the introduction of sclerosing foam by the controlled injection into the refluxing superficial vein under ultrasound guidance. Sclerotherapy is an endoablative, non-tumescent, very useful method to treat VVs, and probably, is less expensive than other methods. However, until now, it is not subjected to scientific scrutiny as other methods of endoablation -an art waiting for its science. ${ }^{[41]}$ Despite the other endoablative methods, such as thermal endoablation (i.e., laser, radiofrequency and steam), chemical endoablation by FS is an attractive technique, as the requirement for tumescence, anesthesia and hospital admission are avoided. It also utilizes minimal paraphernalia used for obtaining a sterile operative field..$^{[42]}$ Color Doppler vascular ultrasound is indispensable for this procedure and helps to monitor the site, amount and outcome of the sclerosant to generate a sclerosis/occlusion of the vein and can detect the minutest of the reflux relapses. ${ }^{[43]}$

The foam is produced by mixing a sclerosing agent with room air or a physiological gas and can be used to treat saphenous tributaries, perforators, as well as truncal reflux, particularly in advanced cases with skin lesions and ulcers. ${ }^{[44,45]}$

Several researchers have reported successful sclerotherapy outcomes for the treatment of lower-extremity VVs. For successful sclerotherapy, adequate clinical and anatomic assessments must be performed prior to the treatment and must be planned in the correct sequence of the order of the reflux points and planning from larger to smaller caliber VVs or even vice versa. This low-cost, minimally invasive method is usually well-tolerated by patients. For clinicians, the direct visualization, localization, and quantification of venous reflux with $95 \%$ sensitivity and $100 \%$ specificity is of immense importance. Although UGFS is well-tolerated by the patients with infrequent major complications, it is recommended to continue to assess any post-procedural complications with vigilance and alertness.
The commonly used sclerosants are classified into detergents, chemical irritants, and osmotic agents. Detergents such as sodium morrhuate, ethanolamine oleate, STS, and polidocanol destroy vein cell membrane through protein denaturation. The mechanism of action of STS is based on the disruption of the intercellular cement between the endothelial cells and is commonly used in concentrations of $0.5-3 \%$ to sclerose lower limb VVs. The maximum dose for STS is $10 \mathrm{~mL}$ of $3 \%$ solution as per different guidelines.

Polidocanol is quite popular in Europe. Polidocanol is a synthetic fatty alcohol with detergent activity causing endothelial cell death. It is used in concentrations of $0.25-6 \%$ to sclerose lower limb VVs and telangiectasias. Sodium morrhuate is a biological extract rather than synthetic compound and is approved by the United States Food and Drug Administration (FDA) for the treatment of vascular ectasias of the lower extremity. Ethanolamine oleate is a synthetic preparation of oleic acid and ethanolamine that has weak detergent properties. Osmotic agents damage the cell by shifting the water balance through cellular gradient (osmotic) dehydration and cell membrane denaturation. They include hypertonic sodium chloride solution, hypertonic dextrose/glucose and sodium chloride solution with dextrose. The principal advantage of hypertonic saline and dextrose/glucose is the fact that they are naturally occurring agent with no molecular toxicity. ${ }^{[25]}$

All these pharmacologic agents adhere to stringent safety standards, and sclerosants used in obliterative therapy are no exception. The UGFS has evolved over the last three decades to a level where the patient safety is extremely high. The use of physiological gases and volumes of foam not more than $10 \mathrm{~mL}$ in one session has resulted in a fair standardization of treatment across the globe. Guidelines have evolved and the latest reiteration has been published. ${ }^{[46]}$ From personal communications, some experts have indicated that they carry out another session after waiting for $2 \mathrm{~h}$, as the chances of having any systemic complications are back to pre-procedure levels by then.

Hyperpigmentation and matting are the most often local adverse events (AEs) of sclerotherapy. Other local AEs include superficial thrombophlebitis, pyoderma gangrenosum, pain, ulcer formation, and hypertrichosis. Local AEs can be serious and include cutaneous necrosis, intra-arterial injection with subsequent acute ischemia that can lead to amputation, and necrotizing fasciitis. ${ }^{[25]}$ 
Complications from UGFS can be further reduced by:

1. Avoiding treatments in patients with history of asthma, migraine, allergies and known right-to-left shunts

2. Using ultrasound guidance

3. Foaming with physiological gases

4. Sourcing sclerosants from pharmaceutical companies following good manufacturing practices

5. Using appropriate concentrations of sclerosants

6. Using uniform injection pressure

7. Limiting volume of foam to not more than $10 \mathrm{~mL}$ per session

8. Appropriate use of antihistamines and endothelin antagonists or endothelin-receptor blockers

Sodium tetradecyl sulfate, polidocanol, and 50 to $75 \%$ dextrose/glucose are the commonest sclerosants in use all over the world and, considering their widespread use, chemical endoablation with UGFS is well-suited for use in any geographical location and requires minimal infrastructure which is available almost everywhere. ${ }^{[47,48]}$ Sclerosants are deactivated very rapidly in the blood and several in vitro studies have shown that even small quantities of blood deactivate sclerosants. ${ }^{[49]}$ This implies that activity of sclerosant is limited to a short distance.

In conclusion, sclerotherapy, specificallyultrasound guided technique, is an effective and very safe treatment option. When practiced by trained hands with good techniques with appropriate radiological imaging, is very well-tolerated. It is essential to follow general precautions, and posttreatment compliance to avoid adverse events. The adverse events usually are mild and rare; however, it is essential for the facility to be equipped for any emergencies to avoid and deal with serious consequences. Anaphylactic shock is a serious event and, therefore, documenting a thorough medical history of the patient before planning the procedure is mandatory. Oxygen support and emergency medical service for hospitalization must be available.

Over the years, the quality of sclerosants has improved. There are almost no impurities and, hence, the propensity of allergic and cutaneous skin reactions is remarkably reduced. Minor complications, such as telangiectatic matting and hyperpigmentation subside over time; accurate information by counselling the patients help in reducing anxiety and one can expect cooperation from the patient, as well compliance. Compared to liquid sclerotherapy, foamed sclerosing agents have a better tolerance and acceptability profile.

\section{Declaration of conflicting interests}

The authors declared no conflicts of interest with respect to the authorship and/or publication of this article.

\section{Funding}

The authors received no financial support for the research and/or authorship of this article.

\section{REFERENCES}

1. Perrin M, Ramelet AA. Efficacy of venoactive drugs in primary chronic venous disease. Survey of evidence, synthesis and recommendations. In: Bergan JJ, Bunke N, editors. The Vein Book. 2nd ed. New York: Oxford University Press; 2014. p. 514-27.

2. Piazza G. Varicose veins. Circulation 2014;130:582-7.

3. Nelzén O. Prevalence of venous leg ulcer: The importance of the data collection method. Phlebolymphology 2008;15:143-50.

4. Tisi PV. Varicose veins. BMJ Clin Evid 2011;2011:0212.

5. Yun MJ, Kim YK, Kang DM, Kim JE, Ha WC, Jung KY, et al. A study on prevalence and risk factors for varicose veins in nurses at a University Hospital. Saf Health Work 2018;9:79-83.

6. Jacobs BN, Andraska EA, Obi AT, Wakefield TW. Pathophysiology of varicose veins. J Vasc Surg Venous Lymphat Disord 2017;5:460-7.

7. Goodyear SJ, Nyamekye IK. Radiofrequency ablation of varicose veins: Best practice techniques and evidence. Phlebology 2015;30(2 Suppl):9-17.

8. McCausland S. The modern treatment of varicose veins. Med Press Circ 1939;201:404-10.

9. Foot RR. The injection treatment. In: Foote RR, editor. Varicose veins, haemorrhoids and other conditions. London: Lewis; 1944. p. 13-44.

10. Sigg K. Neuere Gesichtspunkte zur Technik der Varizenbehandlung. Ther Umsch 1949;6:127-34.

11. Orbach EJ. A new approach to the sclerotherapy of varicose veins. Angiology 1950;1:302-5.

12. Fluckiger P. Nicht-operative retrograde Varicenverodung mit Varsylschaum. Schweiz Med Wochenschr 1956;86:1368-70.

13. Wollmann JC. The history of sclerosing foams. Dermatol Surg 2004;3:694-703.

14. Kakkos SK, Bountouroglou DG, Azzam M, Kalodiki E, Daskalopoulos M, Geroulakos G. Effectiveness and safety of ultrasound-guided foam sclerotherapy for recurrent varicose veins: İmmediate results. J Endovasc Ther 2006;13:357-64.

15. Rabe E, Breu FX, Cavezzi A, Coleridge Smith P, Frullini A, Gillet JL, et al. European guidelines for sclerotherapy in 
chronic venous disorders. Phlebology 2014;29:338-54.

16. Jia X, Mowatt G, Burr JM, Cassar K, Cook J, Fraser C. Systematic review of foam sclerotherapy for varicose veins. Br J Surg 2007;94:925-36.

17. Weiss MA, Hsu JT, Neuhaus I, Sadick NS, Duffy DM. Consensus for sclerotherapy. Dermatol Surg 2014;40:1309-18.

18. Miyake RK, King JT, Kikuchi R, Duarte FH, Davidson $\mathrm{JR}, \mathrm{Oba} \mathrm{C}$. Role of injection pressure, flow and sclerosant viscosity in causing cutaneous ulceration during sclerotherapy. Phlebology 2012;27:383-9.

19. Bihari I, Magyar E. Reasons for ulceration after injection treatment of telangiectasia. Dermatol Surg 2001;27:133-6.

20. Schuller-Petrović S, Pavlović MD, Neuhold N, Brunner F, Wölkart G. Subcutaneous injection of liquid and foamed polidocanol: Extravasation is not responsible for skin necrosis during reticular and spider vein sclerotherapy. J Eur Acad Dermatol Venereol 2011;25:983-6.

21. Goldman MP, Sadick NS, Weiss RA. Cutaneous necrosis, telangiectatic matting, and hyperpigmentation following sclerotherapy. Etiology, prevention, and treatment. Dermatol Surg 1995;21:19-29.

22. Mlosek RK, Woźniak W, Malinowska S, Migda B, Serafin-Król M, Miłek T. The removal of postsclerotherapy pigmentation following sclerotherapy alone or in combination with crossectomy. Eur J Vasc Endovasc Surg 2012;43:100-5.

23. Goldman MP, Kaplan RP, Duffy DM. Postsclerotherapy hyperpigmentation: A histologic evaluation. J Dermatol Surg Oncol 1987;13:547-50.

24. Green D. Persistent post-sclerotherapy pigmentation due to minocycline. Three cases and a review of post-sclerotherapy pigmentation. J Cosmet Dermatol 2002;1:173-82.

25. Yiannakopoulou E. Safety concerns for sclerotherapy of telangiectases, reticular and varicose veins. Pharmacology 2016;98:62-9.

26. Kadam P, Lim J, Paver I, Connor DE, Parsi K. Telangiectatic matting is associated with hypersensitivity and a bleeding tendency. Eur J Vasc Endovasc Surg 2018;55:554-9.

27. Davis LT, Duffy DM. Determination of incidence and risk factors for postsclerotherapy telangiectatic matting of the lower extremity: A retrospective analysis. J Dermatol Surg Oncol 1990;16:327-30.

28. Morrison N, Neuhardt DL, Rogers CR, McEown J, Morrison T, Johnson E, et al. Comparisons of side effects using air and carbon dioxide foam for endovenous chemical ablation. J Vasc Surg 2008;47:830-6.

29. Ricci S, Moro L, Antonelli Incalzi R. Ultrasound imaging of the sural nerve: Ultrasound anatomy and rationale for investigation. Eur J Vasc Endovasc Surg 2010;39:636-41.

30. Beckitt T, Elstone A, Ashley S. Air versus physiological gas for ultrasound guided foam sclerotherapy treatment of varicose veins. Eur J Vasc Endovasc Surg 2011;42:115-9.

31. Frullini A, Barsotti MC, Santoni T, Duranti E, Burchielli S, Di Stefano R. Significant endothelin release in patients treated with foam sclerotherapy. Dermatol Surg 2012;38:741-7.
32. Wong M. Should foam made with physiologic gases be the standard in sclerotherapy? Phlebology 2015;30:580-6.

33. Marrocco-Trischitta MM, Guerrini P, Abeni D, Stillo F. Reversible cardiac arrest after polidocanol sclerotherapy of peripheral venous malformation. Dermatol Surg 2002;28:153-5.

34. Hill DA. Neurological and chest symptoms following sclerotherapy: A single centre experience. Phlebology 2014;29:619-27.

35. Stephens R, Dunn S. Non-ST-elevation myocardial infarction following foam ultrasound-guided sclerotherapy. Phlebology 2014;29:488-90.

36. Potter B, Gobeil F, Oiknine A, Laramée P. The first case of takotsubo cardiomyopathy associated with sodium tetradecyl sulphate sclerotherapy. Can J Cardiol 2010;26:146-8.

37. Cifuentes JS, Ulloa JH, Pinto P, Bravo JA, Montenegro AC. Takotsubo Syndrome induced by sclerotherapy with polidocanol. Acta Phlebologica 2020;21:48-51.

38. Dabbs EB, Dos Santos SJ, Mainsiouw LE, Sheikh AA, Gkantiragas A, Shiangoli I, et al. Implication of foam sclerosant inactivation by human whole blood in a laboratory setting. Phlebology 2018;33:338-43.

39. Kulkarni SR, Messenger DE, Slim FJ, Emerson LG, Bulbulia RA, Whyman MR, et al. The incidence and characterization of deep vein thrombosis following ultrasound-guided foam sclerotherapy in 1000 legs with superficial venous reflux. J Vasc Surg Venous Lymphat Disord 2013;1:231-8.

40. Guex JJ, Isaacs MN. Comparison of surgery and ultrasound guided sclerotherapy for treatment of saphenous varicose veins: must the criteria for assessment be the same? Int Angiol 2000;19:299-302.

41. de-Abreu GCG, Camargo O Júnior, de-Abreu MFM, de-Aquino JLB. Ultrasound-guided foam sclerotherapy for severe chronic venous insufficiency. Rev Col Bras Cir 2017;44:511-20.

42. Wright D, Gobin JP, Bradbury AW. Varisolve ${ }^{\circledR}$ polidocanol microfoam compared with surgery or sclerotherapy in the management of varicose veins in the presence of trunk vein incompetence: European randomized controlled trial. Phlebology 2006;21:180-90.

43. Beale RJ, Gough MJ. Treatment options for primary varicose veins--a review. Eur J Vasc Endovasc Surg 2005;30:83-95.

44. Frullini A, Cavezzi A. Sclerosing foam in the treatment of varicose veins and telangiectases: History and analysis of safety and complications. Dermatol Surg 2002;28:11-5.

45. Guex JJ. Ultrasound guided sclerotherapy (USGS) for perforating veins (PV). Hawaii Med J 2000;59:261-2.

46. Rabe E, Breu FX, Flessenkämper I, Gerlach H, Guggenbichler S, Kahle B, et al. Sclerotherapy in the treatment of varicose veins: S2k guideline of the Deutsche Gesellschaft für Phlebologie (DGP) in cooperation with the following societies: DDG, DGA, DGG, BVP. Hautarzt 2020. [Online ahead of print]

47. Bradbury AW, Bate G, Pang K, Darvall KA, Adam DJ. Ultrasound-guided foam sclerotherapy is a safe and 
clinically effective treatment for superficial venous reflux. J Vasc Surg 2010;52:939-45.

48. Varicose Veins, "Cardiovascular disorders - Merck manuals professional edition. merck manuals professional edition," 2019. Available at: https://www.msdmanuals.com/ professional/cardiovascular-disorders/peripheral-venousdisorders/varicose-veins. [Accessed: February, 2021]

49. Watkins MR. Deactivation of sodium tetradecyl sulphate injection by blood proteins. Eur J Vasc Endovasc Surg 2011;41:521-5. 